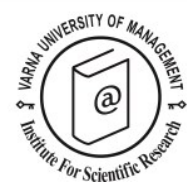

\title{
Co-Designing Smart Tourism
}

\author{
Janne J. Liburd ${ }^{1 *}$, Tanja K. Nielsen ${ }^{2}$ and Chris Heape ${ }^{2}$
}

Received: 20/10/2016 Accepted: 06/02/2017

\footnotetext{
1 University of Southern Denmark, Universitetsparken 1, 6000 Kolding, Denmark; phone: 65501576, e-mail: liburd@sdu.dk

${ }^{2}$ University of Southern Denmark

* Corresponding author
}

\begin{abstract}
Emerging theories of smart tourism are chiefly concerned with how Internet Communication Technology and Big Data can influence marketing, product and destination development. The risk being that an overt focus on formal outcomes, namely technology, products and services, diverts attention from how things and operations are actually achieved. This paper challenges the notions of smart and value co-creation by introducing tourism co-design as a learning and experiment driven development process. Tourism co-design leverages the communicative interaction between people and enables tourism operators to change their practices. Based on fieldwork in the northern part of Denmark we explore how smart tourism can become smarter through tourism co-design processes. We argue that a shift is needed from: How can we efficiently achieve a more or less known goal? To: How can we effectively explore and give sense to something new and engage in processes that encourage the new to emerge? Tourism co-design enables values to transpire at multiple levels and engenders unknown possibilities that inform how smart tourism may be operationalised.
\end{abstract}

Cㅇ 2017 Varna University of Management. All rights reserved

Keywords: Smart tourism, Co-creation, Tourism Co-design, Values, Denmark.

Citation: Liburd, J., T. Nielsen, and C. Heape (2017) Co-Designing Smart Tourism. European Journal of Tourism Research 17 pp. 28-42

\section{Introduction}

The Internet, dynamic technologies and Web 2.0 platforms have enabled change in the way businesses and consumers interact in tourism, but also "the way how and by whom tourism products, services and experiences are designed, created and consumed" (Neuhofer, 2016: 17). Recent academic attention has been on emergent theories of smart tourism which, broadly understood, focus on digital opportunities and data-driven developments to enhance destination competitiveness, tourist experiences and support for new forms of collaboration and value creation (Boes et al., 2015; Gretzel et al., 2015a; Gretzel et al., 2015b). An "output view" embedded in technology and data structures is widespread in smart tourism research (Buhalis, Amaranggana, 2013; Wang et al., 2013; Zacarias et al., 2015; Zhu et al., 2014). But, an overt focus on formal outcomes such as technology, products and services can divert attention from how things and operations are actually achieved (Sproedt, Heape, 2014). 
In this paper, we argue that an attention to the nuance of practice provides valuable insights (Heape, 2015b). We explore how the concept of smart tourism can be developed to reach beyond a technical, data driven and end-user outcome logic. We also argue that ideals of smart tourism, such as digital readiness, retrieving and sharing data, do not come about of their own accord. Drawing on fieldwork in northern Denmark, we show that although the terms smart and Big Data carry positive connotations for tourism practitioners, if they have heard of them, they still remain sceptical as to how to situate these in actual practice, and how smart tourism adds value to whom.

We also draw attention to how the complexity generated by the predominance of small and medium sized enterprises in the Danish tourism industry and the limited resources, skills and competences for digital readiness, act as barriers to the development and deployment of smart tourism concepts. We show how Tourism Co-design processes enable new possibilities to emerge that can inform what smart tourism can become and how it may be operationalised. We will introduce the notion of tourism co-design as a learning and experiment driven process that leverages the communicative interaction between people (Heape, 2015a). Tourism co-design engages users, providers, organisations and researchers in a co-generative and co-learning development endeavour (Heape, 2007; Mattelmäki \& Visser, 2011; Sanders \& Stappers, 2008). Tourism co-design can drive tourism development and enable people to change their practices with all those involved in a tourism situation. Outcomes of tourism codesign processes may be the identification of innovations, alternative business prospects, new conceptualisations, strategies, changed organisational practices, and sustainable tourism development opportunities. Although the above perspective on co-design is socially oriented, we do not diminish the role of technology in smart tourism.

First, a critical review of current notions and assumptions about smart tourism is provided. Second, the concept of tourism co-design will be outlined. Third, a series of vignettes will exemplify how tourism practitioners in the northern part of Denmark interpreted the notion of smart by reflecting on their current tourism situation and envisioning alternative opportunities for smart tourism practices. The aim of this paper is to initiate a complementary understanding of smart tourism through tourism co-design that takes into account the fluid, dynamic and ongoing enactments and processes of tourism practice, experience and development. Enactments and processes we consider as situated in practice and that emerge in fields of relations. The overall objective is to explore how tourism co-design, as a learning and experiment driven development process, can help identify and operationalise how smart tourism can become smarter so that values transpire at multiple levels.

\section{Literature review: Smart Tourism as Technology Driven}

Current notions of smart tourism focus on complex systems, environments, networks and technology infrastructures that are supported by Information and Communication Technologies (ICT) (Buhalis \& Amaranggana, 2013; Gretzel et al., 2015a; Guo et al., 2014; Wang, et al., 2016). Smart tourism hinges on the integration of information and intensive use of technology to optimize service delivery, increase the quality of experience consumption, and to improve business and destination management (Del Chiappa \& Baggio, 2015; Errichiello \& Micera 2015; Lamsfus et al., 2015; Xiang et al., 2015; Zhu et al., 2014). Wang et al. (2013) propose a service-dominant logic (SD) to understand the context, necessity, and future directions of smart tourism development (cf. Lusch \& Vargo, 2014; Vargo \& Lusch, 2004, Vargo et al., 2008). Vargo and Lusch (2014) describe the SD logic in service ecosystems as "relatively self-contained, self-adjusting systems of resource-integrating actors that are connected by shared institutional logics and mutual value creation through service exchange" (p. 242).

The SD logic underpinning smart tourism hinges on (generic) actors co-creating value through the integration of resources and exchange of services, coordinated through actor-engendered institutions in nested and overlapping service ecosystems. Afsarmanesh 
and Camarinha-Matos (2000) describe it as the new paradigm of smart organisations: "for tourism is then a temporary consortium of different organizations representing service providers such as travel agencies, accommodation providers, organizers of leisure programs, or public tourism organizations. These organizations join their skills and resources in order to either offer an integrated and aggregated service, or to better answer to a business opportunity, and whose cooperation is supported by computer networks" (p. 456). This seems to rests on an attitude of mind born by the SD creed of 'we deliver what we think you need', where collaboration, innovation and value creation is technology driven.

Many scholars have emphasized the importance of networks and network dynamics that consist of public organisations and private enterprises of different sizes and character to sustain the competitive ability of destinations (Afsarmanesh \& Camarinha-Matos, 2000; Buhalis \& Amaranggana, 2013; Del Chiappa \& Baggio, 2015; Errichiello \& Marasco, 2017; Gretzel et al., 2015; Liburd et al., 2013). Buhalis and Amaranggana (2013) propose that the ultimate aim is "to utilize the system to enhance tourism experience and improve the effectiveness of resource management towards maximizing both destination competitiveness and consumer satisfactions while also demonstrate sustainability over an extended timeframe" (p. 557). This implicates some smart tourism ideals, based on an underpinning system. Yet it remains unclear how these desirable outcomes have been detected, and how the meaning of satisfaction may differ in a service situation, destination development and in tourism experiences, which can be substantially different from service production.

Further problems engendered relate to "an obstacle to a harmonised integrated information system to support enterprises' cooperation" (Afsarmanesh \& Camarinha-Matos, 2000: 457). This exposes a need for digital readiness and other ideals of smart tourism, such as the retrieving and sharing of data. Gretzel et al. (2015b) advocate a systems model to create, manage and deliver intelligent tourist services and experiences. This is described as 'the Smart Tourism Ecosystem'
(Gretzel et al., 2015a; Gretzel et al., 2015b) or a 'Smart Information System' Wang et al., 2016). A smart tourism ecosystem is defined as: "a tourism system that takes advantage of smart technology in creating, managing and delivering intelligent touristic services/ experiences and is characterized by intensive information sharing and value co-creation" (Gretzel et al., 2015a: 560). Although defining smart tourism as an ecosystem may help to clarify its technological elements, a system approach does rather simplify and potentially marginalise issues of context and practice (Gretzel et al., 2015a: 559). Is this line of reasoning technology is not the only layer in smart tourism that makes up a smart tourism destination. Gretzel et al. (2015a: 181) describe how tourists are active participants in creation of efficient and meaningful experience. They also add a business layer which refers to "the complex business ecosystem that creates and supports the exchange of touristic resources and the co-creation of the tourism experience" (ibid: 181).

The challenge is to understand how the interrelated processes involved in smart tourism development are created and sustained and how they come about as ongoing achievements of value to different kinds of actors. Although mentioned in existing research, these socially related issues and the barriers that arise are yet to be more fully explored. In particular, what remains unidentified is how value is created in smart tourism and to whom it is valuable. The notions of value co-creation and value-added services in smart tourism are often tangled and discussed at an abstract level (Gretzel et al., 2015a). We know little about what the resources of those involved are, and how they get things done on a daily basis (Sproedt \& Heape, 2014). 'They' includes the broad range of actors that make up a tourism situation, involving multiple tourists, institutions and organisations of public and private character. As such, an overt technical approach to smart tourism can hinder an appreciation of the social dimensions and practices of those involved. Especially if one is to take into account the fluid, dynamic and ongoing enactments and processes of tourism practice, experience and development in local contexts. 
In this brief and by no means exhaustive review, it seems reasonable to claim that current assumptions and preliminary descriptions of smart tourism unfold in a technical, data driven, system oriented and service-dominant logic. Yet, when reviewing existing literature and some underlying elements in smart tourism it may be questioned whether the notion of smart as principally technologically oriented fully grasps its complexity. As mentioned above, ICT has enabled change in the way businesses and consumers interact in tourism, but also how and by whom tourism knowledge, products, services and experiences are designed, created and consumed (Errichiello \& Marasco, 2017; Liburd, 2012; Neuhofer, 2016; Tribe \& Liburd, 2016).

\section{Tourism Co-Design}

In order to develop the idea of and how smart tourism can become smarter, we will now pursue Collaborative Tourism Design, or Tourism Co-Design, as a complementary understanding of smart tourism that unfolds its complexity and embraces change and learning as a means to enable people to change their practices. We advocate a tourism co-design process that leverages a "collective creativity as applied across the whole span of a design process" (Sanders \& Stappers, 2008: 6). By introducing tourism co-design to smart tourism, we wish to engender a shift from an overt, service delivery orientation to that of tourism co-design that takes its departure point in a notion of designing with, rather than developing for. We wish to bring into play the latent potential that lies waiting to be nurtured if one considers smart tourism development as a social endeavour, the interrelated nature of which is continually evolving, rather than as a linear, rational, managed process that attempts to control the market place.

This begs the question of whether one can shift from: "How can we efficiently achieve a more or less known goal?" to "How can we effectively explore, make and give sense to something new and engage in processes that encourage the new to emerge?" (Sproedt \& Heape, 2015). By taking this perspective we do not intend to ignore the role of, for example, technology or the importance of efficiency, control and concrete measurements of (historical) performance as a basis and goal for organisational decision making (Larsen \& Sproedt, 2013), but we are advocating a more temperate notion of both-and, rather than either-or. Our central tenet is that in order to achieve this change, and in this case leverage a complementary notion of smart tourism, it is only by bringing a keen degree of attention to how people actually get things done, which resources they bring to bear, and how the dynamic and emergent nature of their interrelating unfolds that the ways and means to change tourism practice, experience and business can be informed.

The means, methods, tools and interventions that participants carry out as they explore their task and move from experiment to experiment, we describe as tourism co-design. In order to engage the dynamic sense-making in tourism co-design, participants improvise by deploying a range of sensibilities, skills and practices that are continually adjusted in close relationship with the contingency of the task in hand. Participants respond to the variable complexity of the negotiated collective endeavour through an ongoing improvisation and deployment of expertise, flexibility and imagination that interweave with the unfolding situation (Heape et al., 2015). Learning emerges as thematic patterns of meaning (Stacey, 2003: 325) as design processes, methods, tools and interventions are brought into play in order to explore and expand the inquiry. In this regard learning is also considered as understanding in practice and as situated in that practice (Lave \& Wenger, 1991; Suchman, 1987).

Characteristic to the research and operationalisation of tourism co-design is the degree of reflexive attention to and awareness of the relational nature of its practice. Tim Ingold (2000: 195) describes practice as embedded in the "current of sociality... because people, in the performance of their tasks, also attend to one another... By watching, listening, perhaps even touching, we continually feel each other's presence in the social environment, at every moment adjusting our movements in response to this ongoing perceptual monitoring... For the orchestral musician, playing an instrument, watching the 
conductor and listening to one's fellow players are all inseparable aspects of the same process of action: for this reason, the gestures of the performers may be said to resonate with each other... Or what Schutz (1951: 78) called a 'mutual tuning-in relationship' - is an absolute precondition for successful performance."

Tourism co-design leverages the participatory nature of communicative interaction between people (Stacey, 2001: 128-134). In particular, it is essential for those involved, as researchers or as other participants to develop a sensitivity to the dynamic and emergent nature of the interrelationship between the two; between the whole and the parts, with the one affecting the other. By drawing on this perspective, one can infer that smarter tourism happens when practices change in the emergent processes of negotiating new meaning, new opportunities, new insights, new thinking and new doings of smart tourism. So, instead of considering tourism co-design as solely related to the resolution or development of a specific solution, technology or product one can consider tourism co-design as a continuous process of becoming, where many people change their practices (Tamura, 2012).

We distinguish between co-design and cocreation. In our understanding, co-creation is part of a more encompassing tourism codesign process. Mattelmäki and Visser (2011: 11) describe the difference: "co-design is a process and the planning, adjusting tools and facilitation is built on a mind-set based on collaboration. Co-creation can take place within co-design processes but focuses more on the collective creativity of involved users and stakeholders." As far as we are concerned, the whole thrust of the tourism co-design process aims to innovate and design with those involved where outcomes can be changed attitudes or practice as well as products or services. Tourism co-design activities are more local in nature and their outcome are more specifically oriented to engendering the parts and material from which one can derive new syntheses of understanding that can ultimately be brought together as innovation, concept, service or experience.
Moreover, the notions of co-creation and value co-creation in smart tourism remain rather opaque and overlooked. We contend that values may be lost in co-creation, because the resources of those involved, how they get things done, are not identified as such. Extant smart tourism literature predominantly addresses 'value' in the singular (which may allude to economic gain). Yet, value is often generated in other forms and relations, which may be moral, ethical, aesthetic or intrinsic guides for right action (Liburd \& Becken, 2017). Of importance is that values in tourism codesign will always be in the plural due to the collaborative effort of those involved.

A clarification of the abbreviation of 'co-'in tourism co-design is also needed. Liburd (2013) notes that collaboration distinguishes itself from cooperation. Collaboration does not imply a division of labour, which is often the essence of cooperation. Collaboration requires trust and rests on the hypothesis that the sum of the work is more than its individual parts (ibid: 56). The concept of collaboration underpinning tourism co-design suggests a joint effort of individuals to achieve a shared objective where the actual outcome(s) is likely unknown.

The will to engage in unknown endeavours can be countered by an unwillingness to engage the risk, tension or conflict that makes up the dynamic and emergent environment of such an endeavour. The temptation can be to exert a degree of control by prescribing processes that will predict, plan and altogether rationalise the process. The danger being that the very nature of smart tourism, its unfolding, source of diversity and emergence of new meaning that can lead to innovative potential will be stifled. Equally, an overt focus on the (singular) value of the more formal outcome of a co-creation process, the concept, product or service may divert attention from how things are achieved. Tensions are engendered in tourism co-design through a complex interplay of the (plural) values, hopes, dreams and aspirations of those involved and the inherent constraints of the present. Variations of interpretation in the tensions leverage shifts in understanding, which are ultimately expressed as emergent syntheses or innovation proposals (Sproedt \& 
Heape, 2014). Consequently, the values created by those engaged in a tourism codesign task may differ substantially in the process and the outcome(s) may generate different values at multiple levels.

Using the above as a departure point, tourism co-design is an unfolding rather than a foreclosure, where smarter products, services or concepts emerge from the relational positioning of those involved, which the examples from northern Denmark will illustrate in further detail.

\section{Methodology: collection of design materials}

The research referred to in this paper was designed to explore how smart tourism can become smarter through tourism co-design processes. The co-design material has been generated during six months of fieldwork during 2015 in the region of northern Denmark.

The region is mainly known for its rural/nature areas and coastal tourism, which are the main attractions in Denmark, aside from the capital of Copenhagen. Five of eleven municipalities of the region were included based on geographical spread and diverse tourism characteristics (city, coast, nature, attractions and accommodation). Aalborg is the only exception to the rural context, being the third largest city in Denmark. Fourteen interviews were conducted with representatives from DMOs, tourist attractions including museums, a national park, amusements parks and hotels. The informants included webmasters, marketing directors, project managers and heads of DMOs.

The tourism co-design process included seven stages where materials were co-designed by: 1) A review of existing literature on smart tourism; 2) Fieldwork, selection of participants and an introductory meeting; 3) Individual semistructured interviews conducted face-to-face and by telephone; 4) A co-design workshop; 5) Analysis of interviews and workshop material; 6) A seminar to present and discuss research materials emerging from the fieldwork; and 7) Final analysis and co-authoring of reports and a journal article.
Firstly, the review of existing literature on smart tourism identified the current state of the art and helped prepare for the second stage, fieldwork, selection of participants and introductory meeting. This stage was predominantly explorative to gain deeper understandings of the daily practices of those involved in a tourism situation in northern Denmark. At the meeting, preliminary insights about smart tourism were presented. It also included discussion about the smart tourism phenomenon and local attributes in the represented areas to engage participants in the designing with. The face-to-face and telephone interviews of stage 3 were conducted individually at the respective destination or by telephone. The interviews lasted between 30 and 90 minutes and were semi-structured around four topics: 1) Impressions about what smart tourism is and how it is meaningful in a local context; 2) Future scenarios in smart tourism development; 3 ) The potential of smart tourism; who is involved and what resources are present and needed; and 4) Challenges and limitations in smart tourism development.

Interviews were transcribed verbatim, coded according to four themes and further explored for identifying emerging themes based on theory and new insights from the workshop. All of the materials were subjected to content analysis, which is a commonly employed tool that is useful for uncovering knowledge and new insights from the participants' perspective (Jennings, 2010: 211-213).

Next, participants were invited to a workshop (stage 4) to design with, discuss and provide input to initial findings. The workshop engendered variations of interpretation that leveraged the emergence of new smart tourism insights and understandings, which emerged from the interactions of those involved. The contingent and fluid nature of a co-design process was further engaged by a design game (Vaajakallio, 2012; Vaajakallio \& Mattelmäki, 2014).

The participants were divided into smaller groups, including researchers involved in the project. One of the researchers documented the process by taking photographs. The design game, tailor-made for the purpose of this study, 
was constructed around different scenarios and timeframes (short-, mid- and long-term investments). The participants were allowed to 'operate' in all time horizons. Furthermore, the game involved different types of collaboration, such as a big data platform and a temporary network with mutual interests and shared values. Additionally, the game also involved aspects of data-use to reflect upon which kinds of data were thought to be useful and important. Finally, the design game also opened the discussion of skills and competences needed to practice smart tourism. The participants were invited to explore their own organisation or business, which resources (including skills and competences) and smart tourism goals, and the value(s) they wished to create, and for whom.

Stage five, analysis of interviews and workshop material was evaluated by the researchers and explored for emerging themes. The seminar (stage 6) included additional participants, such as representatives from the national DMO and tourism operators recommended by the informants. Findings were presented at the seminar and a report was handed out, which captured preliminary insights from the fieldwork and tourism co-design processes.

The sixth stage represents our current interpretations of smart tourism in northern Denmark, which have emerged from ongoing discussion and critical evaluation of the design materials. These are described in the form of vignettes to exemplify a number of smart tourism situations and illustrate their complex and multi-faceted nature. The three vignettes in the following analysis draw on a series of quotes, which appear in thematic relationship and as synthesis of meaning.

\section{Analysis and discussion}

As indicated above, we wish to explore how tourism co-design can help identify and operationalise how smart tourism can become smarter so that values transpire at multiple levels, and reach beyond a technical, system oriented and data driven logic. Through the vignettes we will show how the interplay between the social and the technical enable alternative and innovative possibilities to emerge, which can inform what smart tourism can become and how it may be operationalised. The vignettes indicate how a close attention to and perception of the going on of tourism practice and experience can inform alternative notions of smart tourism. They are not exhaustive, but focus on the interaction between providers and tourists, the inherent conflict between smart as an ideal and everyday practice, and the sharing involved in a tourism co-design endeavour.

\section{Bringing tourist providers and tourists closer together}

According to the interviewees, smart tourism was conceived as a heterogeneous "multiple purpose space in which a wide range of activities and people co-exist" (Edensor, 2001: 64). More specifically, smart tourism was considered from two interrelated perspectives consisting of tourism providers and the tourists, which are captured in the first vignette:

I'm thinking there are two angles to this. Something needs to be smart for me as a tourist or for tourists in general, and how can I get a better experience by making all the knowledge we have available to me. If I'm a tourist somewhere, then on the one hand I would like to get inspired and on the other, I know I have a preference. So how can I, in advance, have those preferences fulfilled? It's about tailoring something as tourist. On the other hand, if I think of smart tourism providers, then it needs to be smart for them too... You should look both at the users and the workflow. It's important when you own a business to know how your products are used. How can you optimise your business by using data? There's the business part where we need to be smarter and the user experience where you need to be smarter. You can't see it from just one perspective. (Project manager at a municipality)

For me it [smart tourism] is a very broad area. How do we target tourists and locate where they are? Communicating with them and making sure they receive relevant, onlocation information. So we have a big task to make tourist information as available as possible. (Marketing director at local DMO). 
Drawing on the project manager's line of thinking, smart tourists want to be inspired in relation to the preferences they have already identified through e.g. real-time, tailor-made information. This is also referred to as 'smart information' to anticipate consumer needs and wants and enhance travellers' on-site experiences "based upon a variety of factors, and making recommendations with respect to the choice of context-specific consumption activities such as points of interest, dining and recreation" (Gretzel et al., 2015a: 181). From the industry perspective, the project manager emphasises workflow and the ideals of business optimisation by the use of data "to make better operational decisions and operations" (Gretzel et al., 2015a: 179). In this regard, smartness is considered as a business logic that can provide better user experience. The marketing director is also concerned with the end-user perspective and the delivery of information from the perspective of a visitor centre. Unsurprisingly, the interviewees in general emphasised the importance of providing relevant information to tourists in different activities such as marketing, service delivery or experience design. Interestingly, there was an awareness of the fluid nature of smart and readily attending to what can inform smart:

Again, it's about getting to know each other. The same as when we talk, we gradually tune in to who the other person is. We need to do the same for our guests. If we do that then we'll be sharp. (CEO at DMO).

It's something dynamic (smart tourism) where you get to a deeper level. People and tourists have many faces. I'm sure that even if you have many preferences as an individual and as a tourist, there must be something you can extract from that and use... Just like you feel you need to talk to people to be inspired. I feel the same way. (Project manager at a municipality).

You can get to a deeper level of knowing why people visit your destination. That's what smart tourism is for me. When you can do something better for the guests you have and develop existing products. This also includes making money from it. That's necessary, but more an outcome of the other things. (Webmaster at a DMO).

The quotes reflect a complementary approach to the understanding of smart tourism that is more empathic, flexible, intimate and sustainable by attending to people, their situations and experience, rather than considering the smart as mere data. Perceptions reveal complex negotiations between themselves and the tourists in a dynamic process that can engender new meaning, new opportunities, new insights, new thinking and new doing (Larsen \& Sproedt, 2013). This is especially relevant for product development and deeper insights about tourists in local settings. To gain a more intimate knowledge of tourists by obtaining a deeper understanding about them and considering them to be flexible and situated go beyond traditional market segmentation.

\section{The ideals of smart tourism versus the reality of everyday practice}

As mentioned in the literature review, smart tourism carries opportunistic and positive connotations, yet the interviewees had some general concerns about the gap between theory and practice:

In general, it's a challenge to get the terms translated into something that makes sense... the open data, big data talk too. I think a lot of people are thinking Oh boy, what does it mean? It's easier to just do something else because then we do not have to deal with it. (CEO at DMO)

I don't know about smart tourism, but I have stumbled upon smart culture and I can imagine they are related to each other. I relate that to the use of big data, of which there is a lot of talk, but no one really knows what it can do in practice or at least on the level we are working at. (CEO at DMO)

I haven't used it [smart tourism], but big data is something I have come across. It has become a buzz word without anyone really knowing what they mean when they say big data. They just mean a lot of data, massive amounts, I think. So, it's not a term that has become common yet, but the technology [...] 
it's something like apps or something like that, but that's a symptom of projects. If you've developed a new app or website, then it's considered as evidence of something that came out of a project. (Media \& Communication manager at a museum).

We have introduced our wish to engender a paradigm shift, as regards the how and what of doing tourism practice, that moves from an overt, service delivery orientation to that of participatory innovation that takes its departure point in a notion of innovating and designing with rather than developing for. Drawing on the three quotations above, it becomes clear that the tourism providers currently identify smart tourism as developing for with attention to the self and their perceived lack of data skills and knowledge. Gretzel et al. (2015a: 185) argue that "tourism is not currently a sector that attracts a lot of knowledge workers" and "human resources issues with respect to smart tourism are not typically discussed". These issues also became evident in the interviews:

It's about both human and time resources.

To be frank, there are many places that have enough to be getting on with, so they want others to do stuff they're not used to. We can do that, but we need some funding and people to get involved and help us understand what this [smart tourism] is about. (Marketing director at DMO)

It's not so much that the [tourism] industry is under pressure. It's more that they don't have the time to get acquainted with the new stuff ... which basically means that the industry needs to learn that the smart and ITC is something one has to spend time on. We need to set aside the resources, but that's difficult. (Marketing director at DMO).

Here one can see how the intention to work with smart tourism is simply hindered by mundane issues such as lack of time and money needed for this kind of investment. This results in a passive approach. The following quotes elaborate on how the tourism industry awaits smart tourism to happen, or at best to appear in the quest for inspiration:
I have no basis for knowing what it [smart tourism] is. As soon as I or we are presented with something that can create local connections... It's all so new and everyone is saying Ooooh, big data, that's great. (Project manager at a municipality).

It could be that with this smart tourism one could explore some best cases abroad where tourism development is well done. It could be the Museum for Modern Art in St. Ives in the UK. Tourism has really developed around the concept of modern art and managed to retrieve a notion of the classic narrative. With those best cases one could then see how they fit with smart tourism at some of our own destinations; see what new directions we could develop. I think that if one initiated that kind of development here in Denmark, it would help create dynamic growth. It seems that today many people start from the ground up. (CEO at DMO).

Waiting for smart tourism to happen elsewhere might not be ambitious nor lead to sustainable outcomes. Instead we advocate for a tourism co-design process that aims to innovate and design with those involved and built on a mindset based on collaboration (Mattelmäki \& Visser, 2011; Liburd, 2013). This, however, demands an investment in time and effort to engage and trust others. The following quote touches upon collaboration as not only an interaction between tourism providers, but between all those involved in a tourism situation, including an engagement with tourists:

Where are we when we say smart tourism and what can it actually do in practice in the near future? So we're not talking about 2045 and what we can do with technology at that point in time. That doesn't matter at all. We can only guess about the future. What is it we can do right now to make better use of and become smarter in our process of development and the way we engage with our guests? What can we know about our guests and how we can know more about them without spending $x$ number of $a$ hundred thousand Danish Kroner on a consultant again and again.Start monitoring things, so it runs automatically and use and 
act on that information... Start connecting things. (Team leader for a destination development organisation).

The quote represents general concerns about operationalising smart tourism in the near future without a clear understanding of what it is. However, the team leader also considers smart tourism as something mechanical in the sense that it needs automatic, monitoring features. This aligns with principles from smart cities (Del Chiappa \& Baggio, 2015), but the mention of "connectivity" and "act on that information" also indicates a sociotechnical approach beyond a merely technical and data driven logic. The way we start connecting things can potentially open up for how smart can become smarter with attention to the fluid, dynamic and ongoing enactments in fields of relations and situated practice. The team leader poses an open-ended question of "what is it we can start to do right now to make better use of and become smarter in our process of development and the way we engage with our guests?". In a tourism co-design agenda, this is a starting point, also called 'pre-design' or 'the front end' of the design process that "often referred to as 'fuzzy' because of the ambiguity and chaotic nature that characterise it" (Sanders \& Stappers, 2008: 7). At this stage, it is often not known if the deliverable is a product, a service or an interface etc. (Sanders \& Stappers, 2008). From a tourism co-design perspective this means that in this critical phase a broad range of aspects of smart tourism, other than technology and big data, should be considered and worked with, especially if one aims to ensure value creation at multiple levels.

The previous quote by the museum media and communication manager illustrates the tendency to only consider an end-user, outcome logic: "If you've developed a new app or website, then it's considered as evidence of something that came out of a project." This indicates that experiments in the initial stages of a co-design process have been possibly neglected or not fully explored in terms of determining "what is to be designed and sometimes what should not be designed" (Sanders \& Stappers, 2008: 7). In contrast, the open-ended question posed by the team leader potentially takes a shift from: "How can we efficiently achieve a more or less known goal?" to focus on "How can we effectively explore, make and give sense to "our process of development and the way we engage with our guests" (Team leader) in processes that encourage the new to emerge". The practice of engaging a tourism co-design process with others demands a change in attitude and "it will take sometime before the predominant culture accepts egalitarian idea sharing" (Sanders \& Stappers, 2008: 9). This does not imply that the Danish tourism industry needs to start from scratch, but work with existing collaborations and connections.

\section{The idea of sharing and relations in smart tourism}

What makes smart smarter can be captured in the multi-layered relations and dimensions of social interaction. Technology and data do not do anything on their own unless they are brought into relations and meaningful sharing with others. For smart tourism to become smarter it is that by embracing an ethos of trust and sharing, the material and the immaterial, the digital and the non-digital are engendered and brought into play with others in an overall tourism co-design endeavour. Instead, there is a risk of wasting resources in new developments that already exist or are not in demand:

The interplay between virtual and physical networks is interesting. The virtual has to be supported by something tangible. But if there's no collaboration between those involved, you get a situation where you end up with a hashed job. For example in [the coastal town of] Blokhus you've got a situation where we have three different Blokhus apps, which doesn't really help the tourists. Three of the same is not the same as three times the value. (Project manager at a municipality)

It's really difficult to get the information out. We have apps for the Top of Denmark area [northern Denmark], but it's difficult to get people to download them or use them. (CEO at $D M O)$. 
The quotes touch upon a socio-technical aspect which questions ICT in tourism as solely related to the development of a specific solution, technology or product. Smart tourism is neither simply composed of technical devices, data and digital platforms, nor is it solely concerned with social interrelations. Rather, it emerges from an interaction between the two as a continuous process of "organisational becoming" (Thomas et al, 2011). Another dimension in the quotes brings attention to the role of the user. Without the involvement of users, new developments may become invaluable where "'users' can play cocreating roles throughout a design process, i.e. become co-designers, but not necessarily always. It depends on level of expertise, passion and creativity of the "user'" (Sanders \& Stappers, 2008: 12):

Instead of just going by our gut feeling, as some of us tend to do, and if the region gives us some funding, maybe it would be exciting to involve some users. Involve those ones having on hand so they can tell us if there's something missing ... by going into a dialogue with our guests and segments, and listening to what they say rather than a gut feeling that's basically informed by the tourism industry's own players. Not that one should underrate that, but I reckon it would be a new way of doing things if we develop concepts by involving both the tourism industry and ourselves, and take a look at what our guests, our customers say. (CEO at DMO).

The interviews revealed that current involvement of users mainly takes place in traditional ways such as on location visitor satisfaction surveys. Another way information is gathered is by sharing data between similar businesses. One of the interviewees gave a snapshot of what the resources of those involved are, and how tourism providers get things done on a daily basis:

If I need some information about parameters or something specific, then I'll make a phone call or write an email to the person who knows. Then we share that way. We [other attractions] typically engage with each other. We don't give away all our data to each other, but most of it. We are similar in many ways. We are both competitors, but to a greater extent we're also colleagues and share a lot with each other. (Marketing \& event coordinator at an attraction).

In this example, the information exchange is a joint agreement for mutual benefit. Although the information gathering and sharing is rather simple and low-tech (phone and e-mail) it demonstrates how the reciprocal exchange emerges from the local interactions of those involved (Stacey, 2005; Liburd et al., 2013). Hence, a social dimension is embedded in locally established collaborations and connections. It plays a significant role in both triggering a willingness to share information, but also in locating perceived barriers for an encounter. For example, such a barrier could be a lack of willingness to share data due to competition or context:

I think people keep it [information] tight to protect their competitive advantage. If you have partnerships that are not directly competing with each other, but are a supplementary to your business, then I think it's easier. It's about size too. I know some bigger cities where they have hotels with a shared, anonymous database of statistics. Our town is just too small for that, because everyone would know who the others are. That's the difference. (CEO at a hotel).

The hotel CEO captures the importance of mutual trust in collaborative endeavours. The "competitive advantage" referred to resembles Huxham's notion of "collaborative advantage" (1996: 14). Presented with the option to engage in smart tourism collaboration, individuals or groups will have to decide with whom to collaborate, or not. Such choice entails the exclusion of other individuals or institutions from the inner circle of collaborative practice (Walsh \& Kahn, 2010: 197). How or by whom inclusion and exclusion is decided in the "Smart Tourism Ecosystem" (Gretzel et al., 2015a; Gretzel et al. 2015b) or the 'Smart Information System' (Wang et al., 2016) is not discussed in extant smart tourism literature.

The three central themes and their respective vignettes clearly indicate the broad range of 
responses to what smart tourism is and the relative confusion, scepticism and idealism as to how it can be operationalised. Equally the reality of everyday practice and inter-relational nature of collaboration between business to business or between tourism operators, developers and tourists also stand out as aspects of smart tourism that should be taken into account. Without trust, people are loath to reach out, and to make the social connections that underpin any collaborative action (Helliwell \& Wang, 2009). In other words, the three vignettes represent a field of relationships thick with the sociality of complex responsive processes of relating (Stacey et al., 2000; Shaw \& Stacey, 2006; Buur \& Larsen $2010 a \& b)$. In order to capture the point about 'thick' relations in smart tourism, Geertz' (1973) point about making 'thick descriptions' is illustrative. By reference to Gilbert Ryle, the author argued that if someone winks at us without a context, we don't know what it means. We can report on the wink ('thin description'). If we provide a context we will know if the person is attracted to us, or that $\mathrm{s} /$ he is trying to communicate secretly, or that s/he has something in his/her eye ('thick description'). As the context changes, the meaning of the wink changes. A 'thick description' of social relations in a smart tourism situation would help render the behaviour, context and values meaningful not just for but with others, and thus enable people to change their practices.

One can then ask, what is needed to help shift that everyday practice? Of note in the vignette "Bringing tourist providers and tourists closer together" is the following snippet from a DMO manager: "Again, it's about getting to know each other. The same as when we talk, we gradually tune in to who the other person is. We need to do the same for our guests. If we do that then we'll be sharp." This relational tuning-in of practice links to Tim Ingold's (2000: 195) point above, where he describes practice as embedded in the "current of sociality... because people, in the performance of their tasks, also attend to one another..." In all of the vignettes a social dimension is either being played out, as with the hotel CEO and marketing \& event coordinator's emails and phone calls. The potential of the social as generative is anticipated as in the case of the CEO at a DMO who advocated involving users to inform their development process. The social is embedded in aspirations for smart and it is only by bringing an attuned perception and appreciative awareness into play (Heape, $2015 \mathrm{~b})$ and really attending to and unfolding the ongoing nuance, complexity, dynamic, emergent and inter-relational nature of the social going on that one can begin to make smart smarter.

\section{Conclusion and implications for future research}

The aim of this paper is ambitious. We wish to instigate a paradigm shift in how one considers smart tourism; its research, development and operationalisation. The contribution of this article lies in the complementary understanding of smart tourism through tourism co-design that takes into account the fluid, dynamic and social enactments and processes of tourism practice, experience and development so that values transpire at multiple levels.

We bring forth three complementary considerations of smart tourism. Firstly, what is making smart smarter, or 'thicker' and richer (Geertz, 1973 ) is the nuanced process by which data and understanding, both material and immaterial, digital and non-digital is engendered and brought into play with others in an overall tourism co-design endeavour. The tourism co-design endeavour is not fixed or concluded, but embraces the improvised, the temporal and the emergent as a continually evolving phenomenon. So by embracing the fluid and emergent nature of smart, and responding to it by readily attending to what can inform the smart, one can move from a service dominant logic of 'we deliver what we think you need', to an appreciative approach. It is an appreciative and complementary understanding that is more empathic, flexible, humble and sustainable in as much as practitioners are more inclined to attend to what makes smart smarter, namely people, their situations and experience, and not just blind data. By bringing into play the inter-relational character of the social that leverages the communicative interaction between people, we have provided the basis for re-appraising and re-understanding the going-on of smart tourism 
research and practice. By doing so, we have shown how one can reveal values through tourism co-design, the nuances of the collaborative and relational of smart tourism, which might otherwise be overlooked. Second, we have contended that values in tourism codesign will always be in the plural due to the collaborative effort of those involved, as opposed to value co-creation in the singular. Third, we have argued how deploying a tourism co-design strategy as a means of collaborative design involves trust and others as a designing with rather than as a designing for.

Some limitations should be noted. With an aim to provide a complementary understanding of smart tourism through tourism co-design that takes into account the fluid, dynamic and ongoing enactments and processes of tourism practice, experience and development, it is not in the scope of this paper to further detail those methods and interventions. Nor do we provide further evidence of smarter smart tourism concepts or changed practices in the Northern Denmark, as these are still in the making. Suffice it to say that we have carried out other tourism co-design projects. One example funded by Innovation Fund Denmark is the project entitled "InnoCoast". By visiting and interviewing locals who live in the UNESCO World Heritage Wadden Sea National Park in Southern Denmark and by bringing them together in a series of workshops, we identified, principally from their narratives about life in the area, a number of sustainable tourism and smart tourism opportunities. We have also supervised numerous, semester long student projects at the University of Southern Denmark's MA tourism education, that are carried out in the field with tourists and operators, where we experiment with deploying tourism co-design to both inform tourism research and the design of complementary tourism concepts, services and products, including smart tourism.

As a result of our findings and general thrust of this paper, our future research will be directed at further unpacking just what smart tourism is and unfold the nuance of interplay between the social and the technical, as both a theoretical and a practical endeavor. As such, we aim to continue to experiment with and cultivate tourism co-design projects in order to more fully engage researchers, tourism operators, developers and tourists in bringing complementary approaches to smarter smart tourism into play.

\section{Acknowledgements}

The authors wish to acknowledge associate professor Carina Ren and assistant professor Morten Krogh Petersen, Aalborg University, for their involvement in the early stages of fieldwork.

\section{References}

Afsarmanesh, H., \& Camarinha-Matos, L. M. (2000). Future smart-organizations: a virtual tourism enterprise. In Web Information Systems Engineering, 2000. (Vol. 1, pp. 456-461). IEEE.

Buhalis, D., \& Amaranggana, A. (2013). Smart Tourism Destinations. In Z. Xiang \& I. Tussyadiah (Eds.), Information and Communication Technologies in Tourism 2014 (pp. 553-564). Cham: Springer International Publishing.

Buur, J. \& Larsen, H. (2010a). The Quality of Conversations in Participatory Innovation. CoDesign, 6(3), 121-138.

Buur, J., Larsen, H. (2010b). Crossing Intentions in Participatory Innovation. PDC 2010, 251-254.

Del Chiappa, G., \& Baggio, R. (2015). Knowledge transfer in smart tourism destinations: Analyzing the effects of a network structure. Journal of Destination Marketing \& Management, 4(3), 145-150.

Edensor, T. (2001). Performing tourism, staging tourism $(\mathrm{Re})$ producing tourist space and practice. Tourist Studies, 1(1), 59-81.

Errichiello, L. \& Marasco, A. (2017). Tourism Innovation-Oriented Public-Private Partnerships for Smart Destination Development. In: N. Scott, M. De Martino, \& M. Van Niekerk (Eds.) Knowledge Transfer to and within Tourism. (pp.147 - 166).Emerald Publishing Limited,

Errichiello L. \& Micera R. (2015). Smart Tourism Destination Governance. In: JS Spender, G. Shiuma \& V. Albino (Eds.) Culture, Innovation and Entrepreneurship: connecting the knowledge dots, (pp. 2179- 
2191), Proceedings of IFKAD 2015 International Forum on Knowledge Asset Dynamics, 10-12 June, Bari.

Geertz, C. (1973). The Interpretation of Cultures. Selected Essays. New York: Basic Books

Gretzel, U., Sigala, M., Xiang, Z., \& Koo, C. (2015a). Smart tourism: foundations and developments. Electronic Markets, 25(3), 179-188.

Gretzel, U., Werthner, H., Koo, C., \& Lamsfus, C. (2015b). Conceptual foundations for understanding smart tourism ecosystems. Computers in Human Behavior, 50, 558563.

Guo, Y., Liu, H., \& Chai, Y. (2014). The embedding convergence of smart cities and tourism internet of things in China: An advance perspective. Advances in Hospitality and Tourism Research, 2(1), 54-69.

Heape, C. R. A. (2007). The Design Spaces the design process as the construction, exploration and expansion of a conceptual space (PhD dissertation). University of Southern Denmark, Denmark.

Heape, C., Larsen, H., \& Revsbæk, L. (2015). Participation as taking part in an improvised temporal unfolding. 5th Decennial Aarhus Conference, Aarhus, Danmark.

Helligwell, J.F. \& Wang, S. (2009). Trust and Well-being. The 3rd OECD World Forum on "Statistics, Knowledge and Policy" Charting Progress, Building Visions, Improving Life. Retrieved on March 30, 2017.

URL:http://www.oecd.org/site/progresskore a/44109590.pdf

Huxham, C. (1996). Creating collaborative advantage. Sage.

Ingold, T. (2000). The Perception of The Environment: Essays in livelihood, dwelling and skill. London and New York: Routledge.

Jennings, G. (2010). Tourism Research (2nd edn.). Australia: John Wiley \& Sons Australia Ltd.

Kim, J.-Y., \& Canina, L. (2015). An analysis of smart tourism system satisfaction scores: The role of priced versus average quality. Computers in Human Behavior, 50, 610617.
Lamsfus, C., Martín, D., Alzua-Sorzabal, A., \& Torres-Manzanera, E. (2015). Smart Tourism Destinations: An Extended Conception of Smart Cities Focusing on Human Mobility. In I. Tussyadiah \& A. Inversini (Eds.), Information and Communication Technologies in Tourism 2015 (pp. 363-375). Cham: Springer International Publishing.

Larsen, H., \& Sproedt, H. (2013). Researching and Teaching Innovation Practice. Proceedings from 14th International CINet Conference, "Business Development and Co-creation" 8-11 September 2013, Nijmegen, Netherlands.

Lave, J. \& Wenger, E. (1991) Situated learning. Cambridge: Cambridge University Press.

Liburd, J.J. (2012) Tourism Research 2.0. Annals of Tourism Research, 39(2), 883907.

Liburd, J.J. (2013).The Collaborative University. Lessons from Tourism Education and Research. Professorial Dissertation. University of Southern Denmark. Odense: Print \& Sign.

Liburd, J.J., \& Becken, S. (2017). Values in nature conservation, tourism and UNESCO World Heritage Site stewardship. Journal of Sustainable Tourism, 1-17 (forthcoming).

Liburd, J.J., Carlsen, J. \& Edwards, D. (Eds.) (2013) Networks for Sustainable Tourism Innovation: Case studies and cross-case analysis. Melbourne: Tilde University Press.

Lusch, R. F., \& Vargo, S. L. (2014). The service-dominant logic of marketing: Dialog, debate, and directions. Routledge.

Mattelmäki, T., \& Visser, F. S. (2011). Lost in Co-X: Interpretations of co-design and cocreation. 4th World Conference on Design Research (IASDR 2011). Delft, The Netherlands.

Neuhofer, B. (2016). Innovation through Cocreation: Towards an Understanding of Technology-Facilitated Co-creation Processes in Tourism. In Open Tourism Open Innovation, Crowdsourcing and Cocreation Challinging the Tourism Industry. Springer-Verlag New York Dordrecht London.

Sanders, E. B.-N., \& Stappers, P. J. (2008). Co-creation and the new landscapes of design. CoDesign, 4(1), 5-18. 
Schutz, A. (1951). Making Music Together - A Study in Social Relationship. Social Research, 18(1), 76-97.

Shaw P., \& Stacey R. (Eds.). (2006). Experiencing Risk, Spontaneity and Improvisation in Organizational Change. London and New York: Routledge.

Sproedt, H., \& Heape, C. (2014). Cultivating Imagination Across Boundaries: Innovation practice as learning through participatory inquiry. Paper presented In 15th INternational CINet ConferenceContinuous Innovation Network. Continuous Innovation Network (CINet).

Stacey, R., Griffin, D., \& Shaw, P. (2000). Complexity and Management: Fad or radical challenge to systems thinking. London and New York: Routledge.

Stacey R. (2001). Complex Responsive Processes in Organisations. London and New York: Routledge.

Stacey, R. (2003). Learning as an activity of interdependent people. The Learning Organization, 10(6), 325-331.

Stacey, R., \& Griffin, D. (2005). A Complexity Perspective on Researching in Organizations. Taking Experience Seriously. London: Routledge.

Suchman, L. A. (1987). Plans and situated actions: The problem of human-machine communication. Cambridge university press.

Tamura, H. (2012). Keynote presentation in Tunstall, E. \& Buur, J. (Eds.) 2012, Proceedings Participatory Innovation Conference 2012: PIN-C 2012. University of Southern Denmark.

Thomas, R. et al. (2011). Managing Organizational Change: Negotiating Meaning and Power-resistance Relations. Organization Science, 22(1), 22-41.

Tribe, J., \& Liburd, J.J. (2016). The Tourism Knowledge System. Annals of Tourism Research, 57: 44-61.

Vaajakallio, K. (2012). Design games as a tool, a mindset and a structure. PhD Thesis defended at the Aalto University, Department of Design.
Vaajakallio, K., \& Mattelmäki, T. (2014). Design games in codesign: as a tool, a mindset and a structure. CoDesign, 10(1), 63-77.

Vargo, S. L., \& Lusch, R. F. (2004). Evolving to a new dominant logic for marketing. Journal of Marketing, 68(1), 1-17.

Vargo, S. L., \& Lusch, R. F. (2008). Servicedominant logic: continuing the evolution. Journal of the Academy of Marketing Science, 36(1), 1-10.

Vargo, S. L., Maglio, P. P., \& Akaka, M. A. (2008). On value and value co-creation: $A$ service systems and service logic perspective. European Management Journal, 26(3), 145-152.

Walsh, L., \& Kahn, P. (Eds) (2010) Collaborative working in higher education. The Social Academy. New York and London: Routledge.

Wang, D., Li, X. (Robert), \& Li, Y. (2013). China's 'smart tourism destination' initiative: A taste of the service-dominant logic. Journal of Destination Marketing \& Management, 2(2), 59-61.

Wang, X., Li, X. (Robert), Zhen, F., \& Zhang, J. (2016). How smart is your tourist attraction? Measuring tourist preferences of smart tourism attractions via a FCEM-AHP and IPA approach. Tourism Management, 54, 309-320.

Xiang, Z., Tussyadiah, I., \& Buhalis, D. (2015). Smart destinations: Foundations, analytics, and applications. Journal of Destination Marketing \& Management, 4(3), 143-144.

Xiang, Z., Tussyadiah, I., Buhalis, D. (2015). Special Issue: Smart destinations. Journal of Destination Marketing \& Management, 4(3), 143-201.

Zacarias, F., Cuapa, R., De Ita, G., \& Torres, D. (2015). Smart Tourism in 1-Click. Procedia Computer Science, 56, 447-452.

Zhu, W., Zhang, L., \& Li, N. (2014). Challenges, function changing of government and enterprises in Chinese smart tourism. Information and Communication Technologies in Tourism. Dublin: Springer. 